OPEN ACCESS

Edited by:

Janos G. Filep,

Université de Montréal, Canada

Reviewed by:

Barnali Biswas,

National Institute for Research in

Reproductive Health (ICMR), India

Sarah McKenna

Midwestern University Arizona College

of Osteopathic Medicine,

United States

${ }^{*}$ Correspondence:

Miguel A. Zarate

miguel.zarate@cuanschutz.edu

Specialty section:

This article was submitted to

Molecular Innate Immunity,

a section of the journa

Frontiers in Immunology

Received: 08 May 2021

Accepted: 13 August 2021

Published: 01 September 2021

Citation:

Zarate MA, De Dios RK, Balasubramaniyan D, Zheng $L$,

Sherlock LG, Rozance PJ and Wright CJ (2021) The Acute Hepatic $N F-\kappa B-M e d i a t e d$ Proinflammatory

Response to Endotoxemia Is Attenuated in Intrauterine Growth-

Restricted Newborn Mice.

Front. Immunol. 12:706774. doi: 10.3389/fimmu.2021.706774

\section{The Acute Hepatic NF-кB-Mediated Proinflammatory Response to Endotoxemia Is Attenuated in Intrauterine Growth-Restricted Newborn Mice}

\author{
Miguel A. Zarate*, Robyn K. De Dios, Durganili Balasubramaniyan, Lijun Zheng, \\ Laura G. Sherlock, Paul J. Rozance and Clyde J. Wright
}

Section of Neonatology, Department of Pediatrics, Children's Hospital Colorado, University of Colorado School of Medicine, Aurora, CO, United States

Intrauterine growth restriction (IUGR) is a relevant predictor for higher rates of neonatal sepsis worldwide and is associated with an impaired neonatal immunity and lower immune cell counts. During the perinatal period, the liver is a key immunological organ responsible for the nuclear factor kappa B (NF-kB)-mediated innate immune response to inflammatory stimuli, but whether this role is affected by IUGR is unknown. Herein, we hypothesized that the newborn liver adapts to calorie-restriction IUGR by inducing changes in the NF- $\mathrm{KB}$ signaling transcriptome, leading to an attenuated acute proinflammatory response to intraperitoneal lipopolysaccharide (LPS). We first assessed the hepatic gene expression of key NF-kB factors in the IUGR and normally grown (NG) newborn mice. Real-time quantitative PCR (RT-qPCR) analysis revealed an upregulation

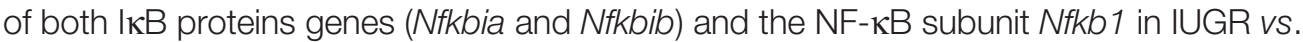
NG. We next measured the LPS-induced hepatic expression of acute proinflammatory genes (Cc/3, Cxcl1, I/1b, I/6, and Tnf) and observed that the IUGR liver produced an attenuated acute proinflammatory cytokine gene response (I/1b and Tnf) to LPS in IUGR vs. unexposed (CTR). Consistent with these results, LPS-exposed hepatic tumor necrosis factor alpha (TNF- $\alpha$ ) protein concentrations were lower in IUGR vs. LPS-exposed NG and did not differ from IUGR CTR. Sex differences at the transcriptome level were observed in the IUGR male vs. female. Our results demonstrate that IUGR induces key modifications in the $\mathrm{NF}-\kappa \mathrm{B}$ transcriptomic machinery in the newborn that compromised the acute proinflammatory cytokine gene and protein response to LPS. Our results bring novel insights in understanding how the IUGR newborn is immunocompromised due to fundamental changes in NF- $\mathrm{KB}$ key factors.

Keywords: liver, innate immunity, LPS, NF-KB, cytokines, sepsis, intrauterine growth restriction 


\section{INTRODUCTION}

Worldwide, intrauterine growth restriction (IUGR) affects approximately $10 \%$ of all newborns (1). Compared to normally grown controls, growth-restricted newborns are at increased risk of infection early in life (2-5). IUGR has been associated with an impaired cellular and humoral immunity characterized by lower white blood cell counts $(5-7)$ and proliferation rates $(8,9)$. Nevertheless, the molecular mechanisms by how IUGR increases susceptibility to infection in the offspring in the perinatal period are yet to be understood.

The transcription factor NF- $\mathrm{KB}$ is intrinsic among all living species (10-14) and coordinates a proinflammatory transcriptional program in response to various infectious stimuli. During the perinatal period, nuclear factor kappa B $(\mathrm{NF}-\mathrm{KB})$ signaling has a protective key role as a regulator of the acute phase innate immune response and immune organ development (15). Reduced NF- $\kappa B$-mediated proinflammatory signaling has been associated with poor immune cell differentiation and activation (16), apoptosis (17), and decreased ability to respond to infection (18). Importantly, recent studies have linked the $\mathrm{NF}-\mathrm{\kappa B}$ innate immune transcriptome to multiple factors that control nutrient metabolism, cell survival, and organ development (19-21). These same pathways are severely affected in target organs in the growth-restricted fetus and neonate, including the liver (22-25).

Besides its metabolic functions during the fetal and perinatal period, the liver plays a key role in regulating the innate immune response due to its essential activity in clearing different antigens from the systemic circulation (26-29). NF- $\mathrm{KB}$ signaling in the liver is very active during development (30) due to its essential roles in tissue integrity (31), maturation of resident macrophages $(12,32)$ and lymphocytes $(16,29)$, and regulating the expression of key factors that are involved in hematopoiesis (33). Hepatic immune cells also contribute to the hepatic NF-KB-mediated innate immune response to different inflammatory stimuli $(29,34,35)$. Our group has previously reported that the liver uniquely contributes to the innate immune response to an inflammatory challenge through the activation of the NF- $\mathrm{KB}$ signaling, which leads to the upregulation of proinflammatory cytokines across different developmental ages $(36,37)$. Furthermore, we have also shown that LPS-exposed fetuses can produce a NF- $\mathrm{KB}$-dependent acute innate immune response, which occurs first and, to a greater degree, in the liver compared to other organs such as the lung and the skin (13). However, competent immune system development and activity requires an appropriate nutrient environment (38), particularly the NF- $\mathrm{KB}$ signaling in the liver, which is energy expensive (30). Therefore, an appropriate in utero environment is necessary for a correct NF- $\mathrm{\kappa B}$ activity in the developing liver. Although the negative impact of IUGR has been described on liver metabolism and structure, its direct effects on the fetal or neonatal NF- $\mathrm{kB}$-mediated hepatic innate immune system have never been explored.

With this in mind, a better understanding of the mechanisms that regulate acute hepatic NF- $\kappa \mathrm{B}$ activation in the IUGR neonate could provide potential therapeutical approaches to prevent morbidity and mortality associated with in utero growth restriction. In the present work, we hypothesized that the newborn liver responds to IUGR by inducing fundamental changes in the expression of key members of the NF- $\mathrm{KB}$ signaling cascade, which leads to an attenuated acute innate immune response to an inflammatory challenge in a murine model of endotoxemia.

\section{MATERIALS AND METHODS}

\section{Ethical Approval}

All animal experiments and procedures were approved by the University of Colorado Institutional Animal Care and Use Committee (00457) and conducted in compliance with the American Association for Accreditation for Laboratory Animal Care at the Perinatal Research Center at the University of Colorado School of Medicine (Aurora, CO, USA).

\section{Murine Model of Intrauterine Growth Restriction}

Our IUGR model was based on a calorie-restricted diet and previously described by Chen and collaborators (39). This model has provided relevant insights on how the fetus adapts to undernutrition conditions in utero, and it has been extensively published (39-42). Briefly, 9-14-week-old C57BL/6 female mice (Jackson Laboratories, Bar Harbor, ME, USA) were allowed to mate with their male counterparts for $24 \mathrm{~h}$ (gestation day E0). Pregnant dams had ad libitum access to food from gestation days E1-E8. At the beginning of gestation day E9-18.5 (fetal tissue collection) or delivery (neonatal experiments), pregnant dams received a $50 \%$ calorie restriction diet (IUGR) or continued with an ad libitum (Control) feeding schedule ( $\mathrm{n}=5-6 /$ group). At the end of the study (gestational day E18.5 or delivery), dams were euthanized with an IP overdose of sodium pentobarbital, and the fetal liver was collected, snap frozen in liquid nitrogen, and stored at $-80^{\circ} \mathrm{C}$. Fetal assessments were conducted in males and females, separately. Newborn mice (P0) were subsequently used for endotoxemia studies.

\section{Murine Model of Endotoxemia}

Neonatal (P0) IUGR and normally grown (NG) C57BL/6 mice ( $\mathrm{n}=$ 5-7/group) were exposed to a sublethal dose of intraperitoneal (IP) LPS ( $5 \mathrm{mg} / \mathrm{kg}$; L2630, Sigma-Aldrich, St. Louis, MO, USA; $1 \mathrm{~h}$ ), as previously reported by our group $(36,37,43,44)$. Similar number of animals from each litter were included as the unexposed (CTR) group. Animals were euthanized with an IP overdose of sodium pentobarbital, and liver regions were collected as described previously, snap frozen in liquid nitrogen, and stored at $-80^{\circ} \mathrm{C}$. Neonatal experiments were performed in male and female mice separately.

\section{mRNA Extraction and Quantitative Real-Time PCR}

Neonatal (P0) hepatic messenger RNA (mRNA) from the right medial lobe was collected using the RNeasy Mini Kit (Qiagen, 
Valencia, CA, USA) and measured for purity and concentration using the NanoDrop (Thermo Fisher Scientific, Waltham, MA). mRNA was converted into complementary DNA (cDNA) using the Verso cDNA synthesis Kit (Thermo Scientific, Waltham, MA, USA). Relative mRNA levels were evaluated by quantitative realtime PCR using the TaqMan gene expression system (Applied Biosystems, Foster City, CA, USA). Hepatic gene expressions of the NF-אB machinery, namely, Chuk (Mm00432529_m1), Ikbkb (mm01222247_m1), Nfkbia (Mm00477798_m1), Nfkbib (Mm00456849_m1), Nfkb1 (Mm00476361_m1), Rela (Mm00501346_m1), and Rel (Mm00485657_m1), and proinflammatory cytokines, namely, Ccl3 (Mm99999057_m1), Cxcl1 (Mm04207460_m1), Il1b (Mm01336189_m1), Il6 (Mm00446190_m1), and Tnf (Mm00443258_m1) in the P0 neonate were assessed with predesigned exon-spanning primers using the StepOnePlus Real-Time PCR System (Applied Biosystems, Foster City, CA, USA). We used the murine housekeeping gene $18 \mathrm{~s}$ to normalize real-time quantitative PCR (RT-qPCR) results, and quantification was performed using the cycle threshold $(\Delta \Delta \mathrm{Ct})$ method as described previously. Samples were run as duplicates, and data are expressed as fold change relative to the mean in the NG and CTR group, respectively.

\section{Detection of Hepatic TNF- $\alpha$ Protein Levels by ELISA}

Liver tissues from IUGR and NG newborn (P0) exposed to IP LPS with their respective controls (CTR) were homogenized using the Bullet Blender (NextAdvance, Troy, NY, USA), and protein concentrations were measured using the bicinchoninic acid (BCA) assay. Hepatic mouse TNF- $\alpha$ values were determined by the mouse TNF alpha uncoated ELISA kit (88-7324, Invitrogen, Carlsbad, CA, USA) according to the manufacturers' protocols. We included negative and positive controls to correct and validate this assay, respectively.

\section{Statistical Analysis}

Statistical analysis was conducted with GraphPad Prism 8 software (GraphPad, San Diego, CA, USA). Calorie-restriction pregnant mice weight was analyzed as a one-way ANOVA (IUGR as a main factor) with time as repeated measurements, and differences between groups were determined by the Dunnett post-hoc test.
IUGR fetal and neonatal parameters (number offetuses and weight) were analyzed by Student's $t$-test, whereas RT-qPCR data were analyzed by the Mann-Whitney $U$ nonparametric test, since gene expression values did not follow the normal distribution. TNF- $\alpha$ ELISA data were analyzed by two-way ANOVA (IUGR and LPS as factors), and difference between groups were determined by Fisher's least significant difference (LSD) test. Both sexes were analyzed separately. Statistical significance was declared at $p<0.05$.

\section{RESULTS}

\section{Calorie Restriction Diet During Pregnancy Induces IUGR in Mice}

Calorie restriction-induced IUGR has been described in different animal models with various outcomes according to the pregnancy states. For this work, we used a modified IUGR murine protocol from Chen and collaborators (39). To validate our IUGR model, we first measured maternal weight and average weight gain across pregnancy starting at gestation age E9 (Figures 1A, B). Calorie restriction significantly reduced maternal weight from gestation age E14 $(p<0.01)$ and maternal average weight gain from gestation age E11 $(p<0.01)$ compared to ad libitum diet (Control) until the end of gestation. We further analyzed fetal and neonatal litter size and weight parameters (Figures 2A-D). Calorie-restriction IUGR did not induce any differences in fetal litter size (Figure 2A) or placental weight (Figure 2B). However, average litter weight at E18.5 was significantly reduced in both IUGR male and female fetuses compared to NG $(p<0.001)$. Similar differences continued in both IUGR male and female P0 neonatal mice compared to NG $(p<0.001)$. There were no sex differences in any parameters described previously.

\section{Calorie Restriction IUGR Modifies the Neonatal Hepatic NF-KB Transcriptomic Machinery}

The innate immune system regulates the fetal and neonatal defense response against pathogen- (PAMPs) or damage-associated molecular patterns (DAMPs) due to a limited antigen exposure in-utero (15). The transcription factor NF- $\kappa$ B plays an essential role
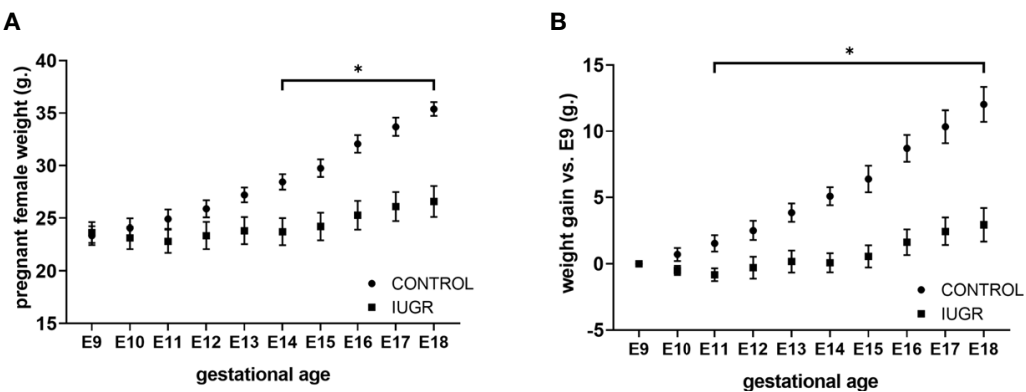

FIGURE 1 | Calorie restriction reduces female weight maternal average gain weight during pregnancy. Pregnant C57BL/6 mice ( $\mathrm{n}=6$ per group) exposed to 50\% calorie restriction diet (IUGR) or ad-libitum (CONTROL) throughout gestation were monitored daily for (A) weight, and (B) weight gain from E9 to E18.5. ${ }^{\star} P<0.05$ vs. IUGR by I-way ANOVA with time as repeated measurements, and the Dunnet Post-hoc test. Values are represented as means \pm SEM. 

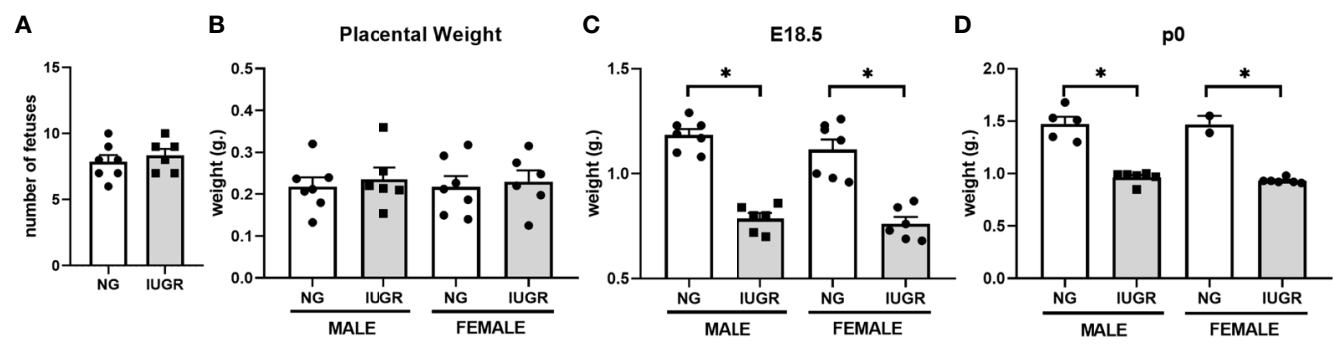

FIGURE 2 | Intra-uterine growth restriction (IUGR) decreases fetal and neonatal weight. Fetal male and female (A) number, and average (B) placental weight, and (C) body weight were measured at E18.5. Each dot represents the mean per litter. (D) Neonatal male and female body weights were measured at P0. ${ }^{*} P<0.05$ vs. IUGR by Student's $t$ test. Values are represented as means \pm SEM.

in the innate immune response $(45,46)$, and we have previously reported its importance in the liver, a key immune organ during the perinatal period. Activation of NF- $\kappa \mathrm{B}$-dependent proinflammatory genes via toll-like receptor (TLR) signaling (47-49) is regulated at different levels. Upregulation of the TLR-mediated proinflammatory cascade depends on the activation of the IKB kinases IKK $\alpha$ and IKK $\beta$ and the degradation of the inhibitory proteins I $\mathrm{I} B \alpha$ and I $\mathrm{B} \beta$, which will further allow the nuclear translocation of the NF- $\kappa B$ subunits p50, p65, and c-Rel (50-52). Although IUGR has been linked to an impaired cellular immunity in humans $(8,53,54)$ and animals $(23,55,56)$, the effects on the hepatic $\mathrm{NF}-\kappa \mathrm{B}$ transcriptomic machinery have never been explored. Figure 3 shows the hepatic gene expression of different NF- $\kappa B$ signaling molecules in male and female P0 NG and IUGR neonates. Gene expression of the IKB kinase Chuk (IKK $\alpha$ ) was significantly higher in the male IUGR neonate compared to NG $(p<0.05)$. Likewise, IUGR showed a significant upregulation of

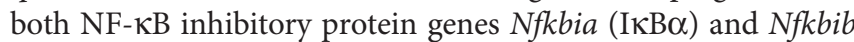
$(\mathrm{I} \kappa \mathrm{B} \beta)$ in male and female neonates versus NG $(p<0.05)$. Similar effects were observed on the IUGR hepatic gene expression of the NF- $\kappa \mathrm{B}$ subunits Nfkb1 in both male and female $(p<0.05)$ and Rela only in male $(p<0.05)$ neonates compared to NG.

\section{The Acute Hepatic Innate Immune Response to an Inflammatory Challenge Is Attenuated in the Neonatal IUGR Liver}

We have previously reported that the liver uniquely contributes to the hepatic innate immune response when exposed to IP LPS through the expression of proinflammatory cytokines $(36,37)$. Since we detected significant changes in the hepatic IUGR NF- $\mathrm{KB}$

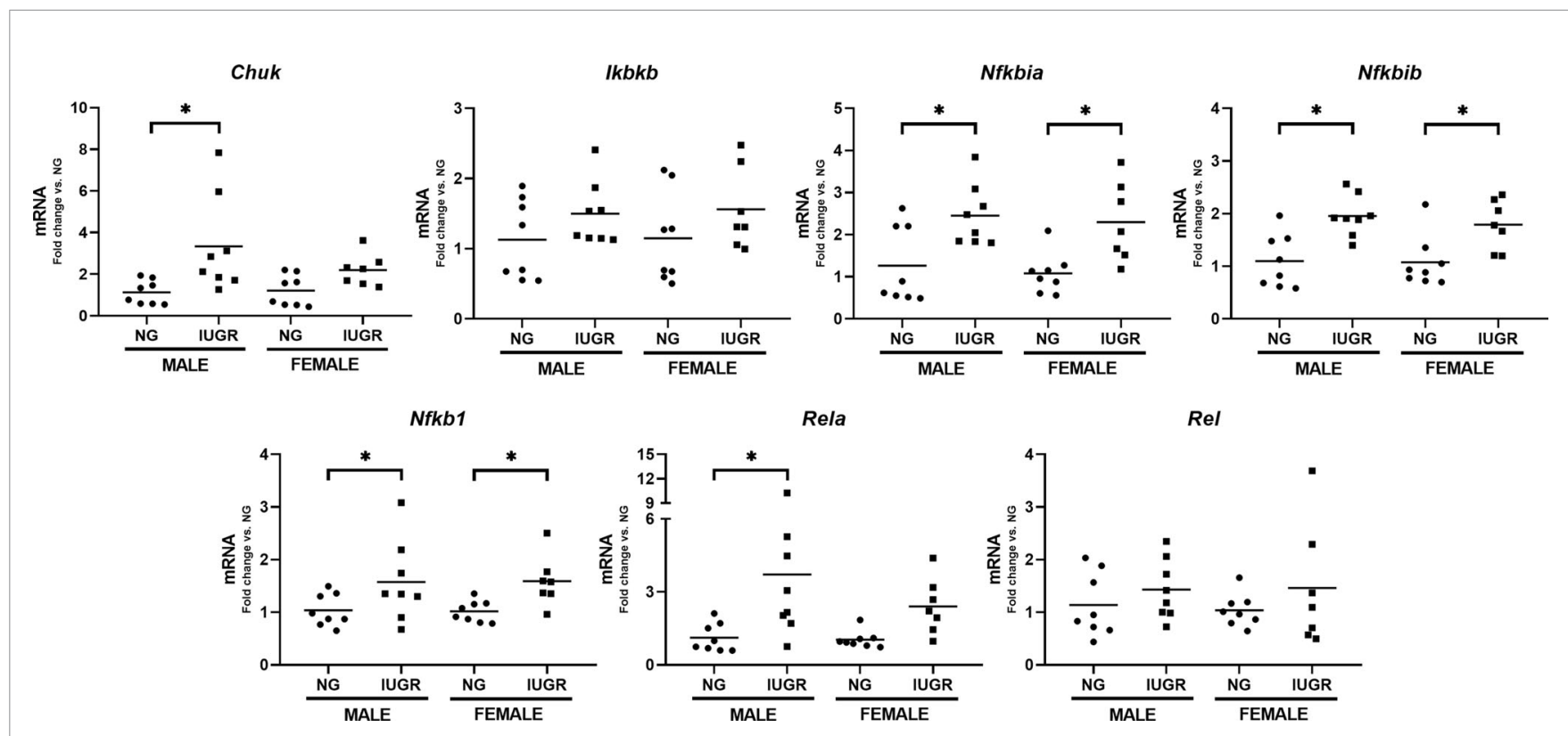

FIGURE 3 | Intra-uterine growth restriction (IUGR) induces changes in the neonatal NF-kB transcriptomic machinery. IUGR and normally (NG) male and female (P0) lives were collected and measured for gene expression of NF- $\mathrm{KB}$ key factors. Mouse $18 \mathrm{~s}$ gene was used a housekeeping gene. ${ }^{\star} P<0.05$ vs. NG by the MannWhitney test. Values are represented as fold change compared to their respective control (NG). 
transcriptomic machinery, we decided to explore the effects of an IP LPS stimulation on the acute hepatic gene expression of key proinflammatory cytokines in the IUGR newborn. Figure 4 shows the hepatic cytokine gene expression of $C c l 3, C x c l 1, I l 1 b$, Il6, and Tnf after $1 \mathrm{~h}$ IP LPS stimulation in the IUGR and NG male and female newborn. IP LPS exposure induced a significant upregulation of all hepatic proinflammatory cytokines in the NG male and female newborn compared to unexposed (CTR) $(p<0.05)$, with the exception of Cxcll in the female mouse. Importantly, LPS exposure did not induce significant changes in the acute hepatic gene expression of $I l 1 b$ and Tnf in both IUGR male and female mice and $\mathrm{Ccl} 3$ and $\mathrm{Cxcl1}$ in male and female mice compared to IUGR CTR, respectively. There were no differences in the LPS-exposed hepatic Il6 gene expression in the NG or IUGR neonate male and female mice compared to their respective CTR.

\section{Calorie Restriction IUGR Attenuates LPS- Induced Hepatic TNF- $\alpha$ Protein Expression Levels in the Newborn}

Having observed important modifications in the NF- $\kappa \mathrm{B}$ and acute proinflammatory cytokines transcriptome profile in the
IUGR newborn compared to NG and the respective CTR after IP LPS exposure, we asked whether these transcriptional differences would affect the expression of at the protein level. Therefore, we decided to measure hepatic levels of TNF- $\alpha$ in the IUGR and NG neonate exposed to IP LPS by ELISA (Figure 5). Exposure to IP LPS significantly increased the hepatic TNF- $\alpha$ levels in the NG male neonate compared to NG CTR and to the LPS-exposed IUGR neonate $(p<0.01)$. TNF- $\alpha$ values in the IUGR male after LPS exposure did not produce any differences compared to the IUGR CTR. Similarly, LPS-exposed NG females tended to have higher hepatic TNF- $\alpha$ values compared to NG CTR $(p=0.066)$ and were significantly higher compared to both LPS-exposed and CTR IUGR newborn $(p<0.05)$.

\section{DISCUSSION}

This study reveals that calorie restriction IUGR is associated with transcriptional changes in the hepatic NF- $\kappa \mathrm{B}$ signaling molecules and an attenuated acute proinflammatory innate immune response to IP LPS in the newborn. This work demonstrates
A
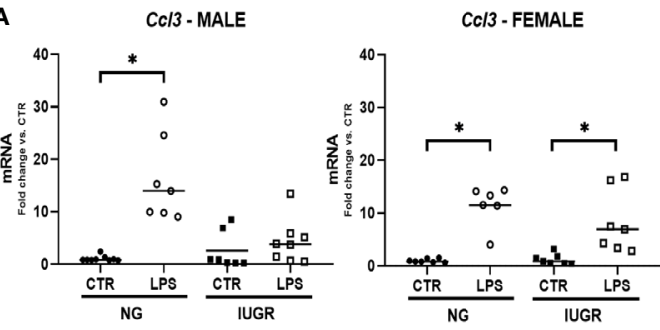

C
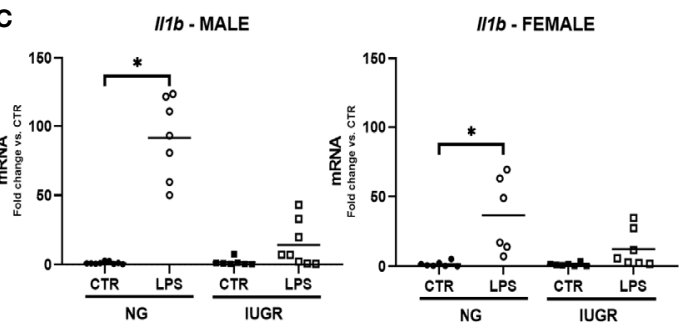
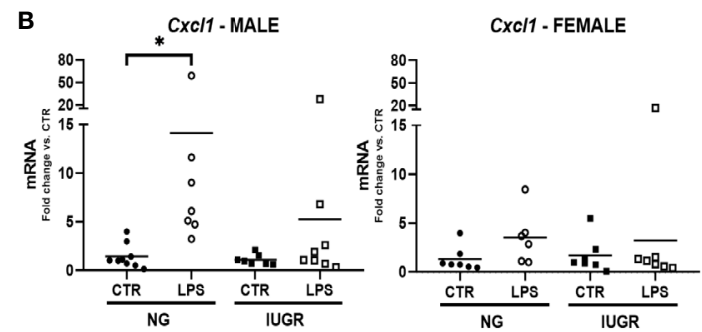

D
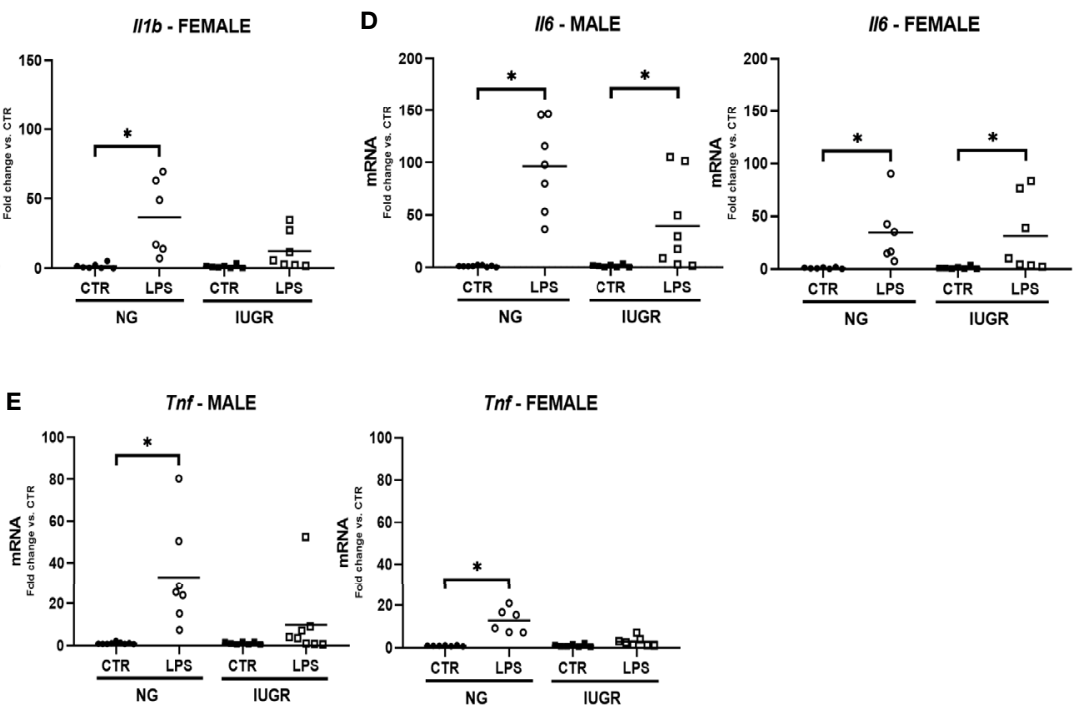

FIGURE 4 | Intra-uterine growth restriction (IUGR) attenuates the hepatic gene expressions of pro-inflammatory cytokines in the LPS-exposed neonate. IUGR and normally grown (NG) male and female neonatal (PO) livers were collected and measured for hepatic gene expression of acute pro-inflammatory markers (A) Cc/3, (B) Cx/1, (C) /11b, (D) $/ 16$, and (E) Tnf at 1-hour post IP LPS. ${ }^{*} P<0.05$ vs. unexposed (CTR) by the Mann-Whitney test. Values are represented as fold change compared to their respective control (CTR). 

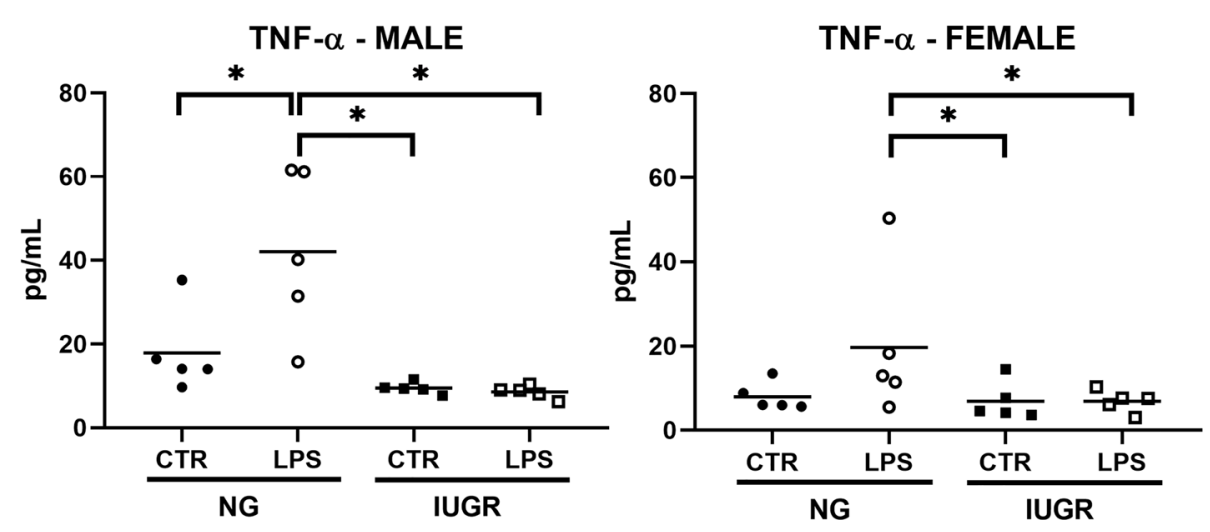

FIGURE 5 | Intra-uterine growth restriction (IUGR) attenuates the hepatic TNF- $\alpha$ protein levels in the LPS-exposed newborn. IUGR and normally grown (NG) male and female neonatal (PO) livers were collected and measured for hepatic TNF- $\alpha$ (pg/mL) protein levels at 1 -hour post IP LPS by ELISA. * $P<0.05$ by 2 -way ANOVA (IUGR and LPS as factors), and Fisher's LSD Post-hoc test. Values are represented as means.

three important findings (1): calorie restriction IUGR induces transcriptomic alterations in key members of the NF- $\mathrm{KB}$ signaling cascade in the neonatal liver. This is characterized by a significant upregulation of both IKB protein genes Nfkbia

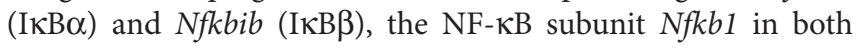
male and female IUGR neonates, and the IкB kinase Chuk (IKK $\alpha)$ and the subunit Rela only in the IUGR male neonate. These fundamental changes were followed by (2) attenuated acute transcriptional proinflammatory cytokine gene response in the IUGR liver after LPS exposure (Illb and Tnf in both male and female IUGR newborns and $\mathrm{Ccl} 3$ and $\mathrm{Cxcl}$ only in the male IUGR), and finally (3), a significant reduction in hepatic TNF- $\alpha$ values in both the LPS-exposed IUGR male and female compared to their respective LPS-exposed NG newborns.

The activation of the NF- $\mathrm{KB}$ signaling is mainly regulated at two levels (1): the NF- $\mathrm{KB}$ kinases (Chuk and Ikbkb genes), which phosphorylate the (2) IKB proteins (Nfkbia and Nfkbib genes) (57). The main role of these IKB proteins is to sequester the NF$\kappa \mathrm{B}$ subunits and prevent their nuclear translocation, thus inhibiting NF- $\kappa \mathrm{B}$-dependent gene transcription of proinflammatory cytokines. Our data indicate that calorie restriction IUGR induces upregulation of Nfkbia (IКB $\alpha$ ) and Nfkbib (ІкB $\beta$ ) hepatic gene expression in male and female neonates and the IкB kinase Chuk (IKK $\alpha$ ) in male mice. Effects on the NF- $\kappa B$ signaling due to alterations of the I $\kappa B$ proteins gene expression have been described previously. For instance, IкB $\alpha$-protein-deficient mouse is reported to have a sustained NF- $\mathrm{KB}$ response with enhanced expression of proinflammatory cytokines (58), and newborns develop severe hematological disorders characterized by a surge in myeloid cells

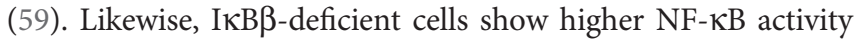
after LPS exposure (60). On the other hand, gene upregulation of I $\kappa \mathrm{B}$ proteins greatly inhibits the induction of the NF- $\kappa \mathrm{B}$ signaling as reported by the use of immunosuppressants such as glucocorticoids (61) and nitric oxide (62). Similarly, overexpression of the I $\kappa \mathrm{B}$ proteins significantly reduces NF- $\mathrm{KB}$ activity and proinflammatory cytokine (TNF- $\alpha$ and IL-1 $\beta$ ) protein expression in myocardial cells (63) and impaired p65 nuclear translocation and reduced inflammation and necrosis in the liver (64).

Furthermore, we have found that the IUGR liver shows an upregulation of the NF- $\mathrm{KB}$ subunits $\mathrm{N} f k b 1$ in both male and female and Rela only in male neonates. The Nfkb1 gene is reported to inhibit the expression of inflammatory genes such as Il12b (65), and Cxcl9, Cxcl10, and $\operatorname{Tnf}(66)$, and increase both gene and protein expression of the anti-inflammatory cytokine Il10 (66) in macrophages. Likewise, p50 subunit (Nfkb1) homodimers can suppress the gene expression of NF- $\kappa \mathrm{B}$-dependent proinflammatory cytokines $(67,68)$. Upregulation of both hepatic IкB proteins (Nfkbia and Nfkbib) and Nfkblgenes in the IUGR newborns might fundamentally alter the acute proinflammatory innate immune response across development and contribute to the IUGR neonatal susceptibility to sepsis. The hepatic NF- $\mathrm{KB}$ transcriptome adaptations to IUGR presented here are novel and can bring important insights on the innate immune development and function in the newborn liver. Furthermore, the balance of the IKB kinases (IKK $\alpha$ and IKK $\beta$ ) can also dictate the NF$\kappa \mathrm{B}$ transcriptome and activation (57), and their adaptations to IUGR also need to be further interrogated. In the present work, we have observed an upregulation of Chuk and Rela genes only in the IUGR male. The gene expression and activity of these key genes has been associated with the induction of the NF- $\mathrm{KB}$ signaling and upregulation of proinflammatory genes in response to an LPS challenge $(69,70)$. Although we detected upregulation of Chuk and Rela in IUGR male mice, which is consistent with a proinflammatory signaling, the expression of acute proinflammatory cytokines was not robust and, in some cases, not different compared to the unexposed mouse. Considering all this information, we speculate that the upregulation of Chuk and Rela occurs as a negative feedback mechanism to an impaired innate immune environment in the IUGR male liver.

Importantly, the transcriptomic changes previously described were associated with implications for the NF-KB-mediated acute proinflammatory cytokine gene response to LPS in IUGR neonatal mice. Our data indicate that IP LPS did not induce a 
robust acute hepatic proinflammatory cytokines gene expression in the IUGR newborn compared to the NG group. An attenuated acute proinflammatory transcriptomic response observed in the IUGR newborn mice was linked to a reduction in hepatic TNF- $\alpha$ cytokine values versus the LPS-exposed NG group.

Although neither IUGR male nor female newborns produced a strong acute hepatic proinflammatory innate immune response to IP LPS, this work reveals for the first time sex differences in this IUGR model. At the transcriptome level, there were more proinflammatory cytokines that did show any significant upregulation in the LPS-exposed IUGR newborn males compared to females (Illb, Tnf, Ccl3, and Cxcl1 vs .Illb and $T n f$, respectively). Our data are supported by other groups who describe the male neonate as more susceptible to infections compared to females $(71,72)$, and this is possibly due to the actions of sexual hormones $(73,74)$. The mechanisms underlying the sex differences in the expression level of key members of the $N F-\kappa B$ signaling cascade in the IUGR newborn are yet to be determined, and this is a critical area for future work. At the protein level, however, acute hepatic TNF- $\alpha$ cytokine values did not differ from CTR after LPS exposure in both IUGR male and female. These data are novel and unique since this is the first time a group has measured the acute hepatic innate immune response to endotoxemia in the IUGR newborn at the transcript and protein level. Our results are supported by Fock et al., who described that peritoneal macrophage from protein-energy malnourished mice showed less NF- $\kappa \mathrm{B}$ activation and TNF- $\alpha$ gene and protein expression after LPS challenge in vitro (18). On the other hand, IUGR is linked to an upregulation of proinflammatory cytokines in the neonatal brain (75-77), with even more exacerbated effects after LPS exposure (78), a complete different response observed in this study in the IUGR neonatal liver where the acute innate immune response to LPS did not differ from CTR. However, for the first time, our work shows how the IUGR liver might be compromised in its response to clearing systemic antigens, which can lead to detrimental effects on the overall health status of the newborn.

Our data are consistent with clinical data from groups who have measured different cytokine profiles in the IUGR human versus control (normally grown). For instance, Lindner et al. found that IUGR infants are immunocompromised due to lower concentrations of G-CSF and IL8 values ( $\mathrm{Cxcl1}$ equivalent in the mouse) in the umbilical cord blood compared to normal-weight babies (79). Likewise, Neta et al. reported that small-forgestational-age babies have lower interferon gamma (IFN- $\gamma$ ) and TNF- $\alpha$ levels in cord blood compared to normally grown babies (80), and Tröger et al. detected lower IL-6 and IL-10 protein levels in LPS-exposed IUGR blood cell cultures (81). Other reports indicate lower anti-inflammatory cytokine values (IL-10 and TGF- $\beta$ ) in the serum of IUGR infants versus their respective normally grown control (53). These studies along with our preclinical observations can provide relevant data to understand the neonatal IUGR innate immune response to a second hit stressor. However, other studies describe that IUGR babies might have a proinflammatory phenotype. For instance, Lausten-Thomsen et al. and Rocha et al. reported higher IL6 $(82,83)$,
IL8 (83), TNF- $\alpha$, and C-reactive protein (2) cytokine values in the IUGR umbilical cord blood compared to normally grown babies, respectively. Such inconsistencies might be attributed to the etiology of the IUGR phenotype (maternal, placental, or fetal origin).

Likewise, IUGR displays different cytokine responses according to the organ of study. For example, reports indicate a significant reduction in anti-inflammatory cytokine values in the IUGR blood and gastrointestinal tract (84) versus normal body weight neonates. On the other hand, IUGR skin (85), spleen (55), and placenta (86) display a greater proinflammatory cytokine expression in the fetus/neonate compared to their respective normally grown group. Given its relevant role as an immune organ in the perinatal period, we decided to investigate the hepatic NF- $\kappa B$ transcriptomic adaptations to calorie restricted IUGR. However, further work should focus on addressing the contribution of other organs to the NF- $\mathrm{KB}$ dependent innate immunity in the IUGR newborn.

The exact mechanisms by which our calorie restriction IUGR model affects the hepatic expression of the IKB proteins and the $N f k b 1$ genes and subsequent activation of proinflammatory responses are still unknown. We speculate that a calorierestricted environment reduces the fetal ATP availability, a relevant substrate required by the $\mathrm{I} \kappa \mathrm{B}$ kinases for the activation of the NF- $\mathrm{KB}$ signaling. A reduction in ATP might lead to the upregulation of both IкB proteins and $N f k b 1$ genes as a protective mechanism to starvation by the fetus at the expense of the activation of NF- $\mathrm{KB}$-dependent proinflammatory cytokine responses and cellular enzymes, which are energy expensive. The inhibition of the NF- $\kappa$ B signaling will allow different fetal tissues to growth and differentiate, thus increasing chances for survival. As a consequence, these NF- $\kappa \mathrm{B}$ transcriptomic modifications can severely compromise the acute hepatic innate response to an inflammatory challenge in the IUGR newborn that might be linked to susceptibility to sepsis and death.

The limitations of this study must be addressed. First, we only measured the IUGR acute hepatic proinflammatory innate immune response to LPS $(1 \mathrm{~h})$ and have not yet assessed these effects at later time points. Reports show that IUGR newborns and children can have prolonged immunity impairment $(8,9)$; thus, there is the need for longer LPS exposures in the IUGR neonate. However, for the first time, this work identified important differences in the IUGR hepatic NF- $\kappa \mathrm{B}$ transcriptome and early proinflammatory cytokine responses to IP LPS. Furthermore, these fundamental changes could potentially be related to the multiple physiological outcomes observed in IUGR neonates such as increasing susceptibility to infections due to a blunted innate immunity. These findings will provide the foundations for testing the response to LPS at different range of exposures (doses), longer time points, and true models of sepsis. Second, we assessed the Toll-like receptor 4 (TLR4)mediated hepatic innate immune response in the IUGR newborn. LPS exposure mimics bacterial infection, an event that is highly correlated with IUGR in the Neonatal Intensive Care Unit (87). Whether these effects will predict similar responses to other DAMPs or PAMPs are yet to be determined. 
This work provides relevant information that will be used for testing the response to other TLR agonists (e.g., CpGs, viral DNA, etc.) at different dosages and later time points. Finally, our assessments were done on whole liver tissues, and we did not account for specific-cell contributions on the innate immune response to LPS in the IUGR newborn. The main goal of this study involved the whole liver since IUGR might have effects on cellular number and/or density, which will make it difficult to compare to normally grown animals. Our results are relevant for future mechanistic studies (e.g., genetic, and pharmacological approaches) that will focus on understanding the role of hepatocytes and hepatic macrophages during TLR4-mediated proinflammatory episodes to create cell-specific therapeutical approaches in the IUGR newborn. Likewise, there are other factors involved in the response to endotoxemia. These factors include hypoxia (88), liver mass (89), nutritional status (90-92), and the presence of free radicals (93), among others. It is possible that these factors could contribute to the cytokine gene expression variability observed in the IUGR newborn exposed to IP LPS. To reduce variability, some IUGR studies identify the smallest or larger animals from the litter as IUGR and NG, respectively $(94,95)$. In this study, however, we used all newborns from IUGR and NG groups despite observing neonatal weight variability within the litter. Taking all these factors into consideration, it was expected to find some variability in the hepatic proinflammatory innate immune response to IP LPS. Still, significant differences between NG and IUGR were observed and reported in this study. Future studies will be conducted to elucidate the effects of all these factors in the IUGR newborn.

We conclude that the liver, a relevant innate immune organ during the perinatal period, responds to calorie restriction IUGR by inducing transcriptomic modifications on NF- $\kappa B$ key factors mainly by upregulation of the IKB proteins ( Nfkbia and Nfkbib) and $N f k b 1$ gene in both male and female newborns. These programming effects were followed by an attenuated hepatic TLR4-dependent acute innate immune cytokine response to IP LPS, which was also observed at the transcriptome and protein level (TNF- $\alpha$ ) in IUGR newborns. Likewise, for the first time, we reported sex differences particularly on both NF- $\mathrm{KB}$ key factors

\section{REFERENCES}

1. Devaskar SU, Chu A. Intrauterine Growth Restriction: Hungry for an Answer. Physiol (Bethesda) (2016) 31(2):131-46. doi: 10.1152/physiol.00033.2015

2. Amarilyo G, Oren A, Mimouni FB, Ochshorn Y, Deutsch V, Mandel D. Increased Cord Serum Inflammatory Markers in Small-for-Gestational-Age Neonates. J Perinatol (2011) 31(1):30-2. doi: 10.1038/jp.2010.53

3. Bernstein IM, Horbar JD, Badger GJ, Ohlsson A, Golan A. Morbidity and Mortality Among Very-Low-Birth-Weight Neonates With Intrauterine Growth Restriction. The Vermont Oxford Network. Am J Obstet Gynecol (2000) 182(1 Pt 1):198-206. doi: 10.1016/s0002-9378(00)70513-8

4. Romo A, Carceller R, Tobajas J. Intrauterine Growth Retardation (IUGR): Epidemiology and Etiology. Pediatr Endocrinol Rev (2009) 6 Suppl 3:332-6.

5. Longo S, Borghesi A, Tzialla C, Stronati M. IUGR and Infections. Early Hum Dev (2014) 90(Suppl 1):S42-4. doi: 10.1016/S0378-3782(14)70014-3
(Chuk and Rela) and acute proinflammatory cytokine (Ccl3 and Cxcl1) gene expression. Future work should center on understanding the relationship between sex hormones and the development of the innate immune system during IUGR. The present work shows how calorie restriction IUGR induces key modifications in the NF- $\kappa \mathrm{B}$ transcriptomic machinery in the newborn mice and bring novel insights on how to treat neonatal sepsis by creating therapeutic approaches targeting specific NF$\kappa \mathrm{B}$ key factors.

\section{DATA AVAILABILITY STATEMENT}

The original contributions presented in the study are included in the article/supplementary material. Further inquiries can be directed to the corresponding author.

\section{ETHICS STATEMENT}

The animal study was reviewed and approved by the University of Colorado Institutional Animal Care and Use Committee.

\section{AUTHOR CONTRIBUTIONS}

Conception and design of research: MZ, CW, PR, and LS. Data collection: MZ, CW, RD, DB, and LZ. Data analysis and interpretation: $\mathrm{MZ}, \mathrm{CW}, \mathrm{PR}$, and LS. Elaboration of manuscript and figures: $\mathrm{MZ}$ and CW. All authors contributed to the article and approved the submitted version.

\section{FUNDING}

The present work was funded by the National Institutes of Health grants R01-HL132941 (CJW), R01-HL132941-02S1 (MZ), R01HD093701 (PR), DK088139 (PR), and T32HD007186 (MZ Trainee, PR PI).

6. Thomas RM, Linch DC. Identification of Lymphocyte Subsets in the Newborn Using a Variety of Monoclonal Antibodies. Arch Dis Child (1983) 58(1):34-8. doi: 10.1136/adc.58.1.34

7. Wirbelauer J, Thomas W, Rieger L, Speer CP. Intrauterine Growth Retardation in Preterm Infants $</=32$ Weeks of Gestation Is Associated With Low White Blood Cell Counts. Am J Perinatol (2010) 27(10):819-24. doi: 10.1055/s-0030-1254547

8. Ferguson AC. Prolonged Impairment of Cellular Immunity in Children With Intrauterine Growth Retardation. J Pediatr (1978) 93(1):52-6. doi: 10.1016/ s0022-3476(78)80599-x

9. Mukhopadhyay D, Weaver L, Tobin R, Henderson S, Beeram M, NewellRogers MK, et al. Intrauterine Growth Restriction and Prematurity Influence Regulatory T Cell Development in Newborns. J Pediatr Surg (2014) 49 (5):727-32. doi: 10.1016/j.jpedsurg.2014.02.055

10. O'Neill LA, Kaltschmidt C. NF-Kappa B: A Crucial Transcription Factor for Glial and Neuronal Cell Function. Trends Neurosci (1997) 20(6):252-8. doi: 10.1016/s0166-2236(96)01035-1 
11. Londhe VA, Nguyen HT, Jeng JM, Li X, Li C, Tiozzo C, et al. NF-kB Induces Lung Maturation During Mouse Lung Morphogenesis. Dev Dyn (2008) 237 (2):328-38. doi: 10.1002/dvdy.21413

12. Espin-Palazon R, Traver D. The NF-kappaB Family: Key Players During Embryonic Development and HSC Emergence. Exp Hematol (2016) 44 (7):519-27. doi: 10.1016/j.exphem.2016.03.010

13. Crampton SJ, O'Keeffe GW. NF-Kappab: Emerging Roles in Hippocampal Development and Function. Int J Biochem Cell Biol (2013) 45(8):1821-4. doi: 10.1016/j.biocel.2013.05.037

14. Eckmann L, Neish AS. NF-kappaB and Mucosal Homeostasis. Curr Top Microbiol Immunol (2011) 349:145-58. doi: 10.1007/82_2010_103

15. Dowling DJ, Levy O. Ontogeny of Early Life Immunity. Trends Immunol (2014) 35(7):299-310. doi: 10.1016/j.it.2014.04.007

16. Doi TS, Takahashi T, Taguchi O, Azuma T, Obata Y. NF-Kappa B RelADeficient Lymphocytes: Normal Development of T Cells and B Cells, Impaired Production of IgA and IgG1 and Reduced Proliferative Responses. J Exp Med (1997) 185(5):953-61. doi: 10.1084/jem.185.5.953

17. Grossmann M, Metcalf D, Merryfull J, Beg A, Baltimore D, Gerondakis S. The Combined Absence of the Transcription Factors Rel and RelA Leads to Multiple Hemopoietic Cell Defects. Proc Natl Acad Sci U S A (1999) 96 (21):11848-53. doi: 10.1073/pnas.96.21.11848

18. Fock RA, Rogero MM, Vinolo MA, Curi R, Borges MC, Borelli P. Effects of Protein-Energy Malnutrition on NF-kappaB Signalling in Murine Peritoneal Macrophages. Inflammation (2010) 33(2):101-9. doi: 10.1007/s10753-0099163-x

19. Covarrubias AJ, Aksoylar HI, Horng T. Control of Macrophage Metabolism and Activation by mTOR and Akt Signaling. Semin Immunol (2015) 27 (4):286-96. doi: 10.1016/j.smim.2015.08.001

20. Dan HC, Baldwin AS. Differential Involvement of IkappaB Kinases Alpha and Beta in Cytokine- and Insulin-Induced Mammalian Target of Rapamycin Activation Determined by Akt. J Immunol (2008) 180(11):7582-9. doi: 10.4049/jimmunol.180.11.7582

21. Baldwin AS. Regulation of Cell Death and Autophagy by IKK and NFKappab: Critical Mechanisms in Immune Function and Cancer. Immunol Rev (2012) 246(1):327-45. doi: 10.1111/j.1600-065X.2012.01095.x

22. Liu J, Yu B, Mao X, He J, Yu J, Zheng P, et al. Effects of Intrauterine Growth Retardation and Maternal Folic Acid Supplementation on Hepatic Mitochondrial Function and Gene Expression in Piglets. Arch Anim Nutr (2012) 66(5):357-71. doi: 10.1080/1745039X.2012.710084

23. Long B, Yin C, Fan Q, Yan G, Wang Z, Li X, et al. Global Liver Proteome Analysis Using iTRAQ Reveals AMPK-mTOR-Autophagy Signaling Is Altered by Intrauterine Growth Restriction in Newborn Piglets. J Proteome Res (2016) 15(4):1262-73. doi: 10.1021/acs.jproteome.6b00001

24. Magee TR, Han G, Cherian B, Khorram O, Ross MG, Desai M. DownRegulation of Transcription Factor Peroxisome Proliferator-Activated Receptor in Programmed Hepatic Lipid Dysregulation and Inflammation in Intrauterine Growth-Restricted Offspring. Am J Obstet Gynecol (2008) 199 (3):271.e1-5. doi: 10.1016/j.ajog.2008.05.022

25. Wesolowski SR, Hay WW Jr. Role of Placental Insufficiency and Intrauterine Growth Restriction on the Activation of Fetal Hepatic Glucose Production. Mol Cell Endocrinol (2016) 435:61-8. doi: 10.1016/j.mce.2015.12.016

26. Gale RP. Development of the Immune System in Human Fetal Liver. Thymus (1987) 10(1-2):45-56. doi: 10.1007/978-94-009-3365-1_6

27. Naito M, Takahashi K, Nishikawa S. Development, Differentiation, and Maturation of Macrophages in the Fetal Mouse Liver. J Leukoc Biol (1990) 48(1):27-37. doi: 10.1002/jlb.48.1.27

28. Naito M, Hasegawa G, Takahashi K. Development, Differentiation, and Maturation of Kupffer Cells. Microsc Res Tech (1997) 39(4):350-64. doi: 10.1002/(SICI)1097-0029(19971115)39:4<350::AID-JEMT5>3.0.CO;2-L

29. Mebius RE, Miyamoto T, Christensen J, Domen J, Cupedo T, Weissman IL, et al. The Fetal Liver Counterpart of Adult Common Lymphoid Progenitors Gives Rise to All Lymphoid Lineages, CD45+CD4+CD3- Cells, as Well as Macrophages. J Immunol (2001) 166(11):6593-601. doi: 10.4049/ jimmunol.166.11.6593

30. Mauro C, Leow SC, Anso E, Rocha S, Thotakura AK, Tornatore L, et al. NFkappaB Controls Energy Homeostasis and Metabolic Adaptation by Upregulating Mitochondrial Respiration. Nat Cell Biol (2011) 13(10):12729. doi: $10.1038 /$ ncb2324
31. Beg AA, Sha WC, Bronson RT, Ghosh S, Baltimore D. Embryonic Lethality and Liver Degeneration in Mice Lacking the RelA Component of NF-Kappa B. Nature (1995) 376(6536):167-70. doi: 10.1038/376167a0

32. Hayden MS, Ghosh S. NF-kappaB in Immunobiology. Cell Res (2011) 21 (2):223-44. doi: 10.1038/cr.2011.13

33. Horwitz BH, Scott ML, Cherry SR, Bronson RT, Baltimore D. Failure of Lymphopoiesis After Adoptive Transfer of NF-kappaB-Deficient Fetal Liver Cells. Immunity (1997) 6(6):765-72. doi: 10.1016/s1074-7613(00)80451-3

34. Luedde T, Schwabe RF. NF-kappaB in the Liver-Linking Injury, Fibrosis and Hepatocellular Carcinoma. Nat Rev Gastroenterol Hepatol (2011) 8(2):10818. doi: $10.1038 /$ nrgastro.2010.213

35. McKenna S, Gossling M, Bugarini A, Hill E, Anderson AL, Rancourt RC, et al. Endotoxemia Induces IkappaBbeta/NF-kappaB-Dependent Endothelin-1 Expression in Hepatic Macrophages. J Immunol (2015) 195(8):3866-79. doi: 10.4049/jimmunol.1501017

36. McKenna S, Eckman M, Parker A, Bok R, Hurt KJ, Wright CJ. Perinatal Endotoxemia Induces Sustained Hepatic COX-2 Expression Through an NFkappaB-Dependent Mechanism. J Innate Immun (2016) 8(4):386-99. doi: $10.1159 / 000445541$

37. McKenna S, Burey T, Sandoval J, Nguyen L, Castro O, Gudipati S, et al. Immunotolerant P50/NFkappaB Signaling and Attenuated Hepatic IFNbeta Expression Increases Neonatal Sensitivity to Endotoxemia. Front Immunol (2018) 9:2210. doi: 10.3389/fimmu.2018.02210

38. Maggini S, Pierre A, Calder PC. Immune Function and Micronutrient Requirements Change Over the Life Course. Nutrients (2018) 10(10):1531. doi: 10.3390/nu10101531

39. Chen PY, Ganguly A, Rubbi L, Orozco LD, Morselli M, Ashraf D, et al. Intrauterine Calorie Restriction Affects Placental DNA Methylation and Gene Expression. Physiol Genomics (2013) 45(14):565-76. doi: 10.1152/ physiolgenomics.00034.2013

40. Baldauf C, Sondhi M, Shin BC, Ko YE, Ye X, Lee KW, et al. Murine Maternal Dietary Restriction Affects Neural Humanin Expression and Cellular Profile. J Neurosci Res (2020) 98(5):902-20. doi: 10.1002/jnr.24568

41. Ganguly A, Touma M, Thamotharan S, De Vivo DC, Devaskar SU. Maternal Calorie Restriction Causing Uteroplacental Insufficiency Differentially Affects Mammalian Placental Glucose and Leucine Transport Molecular Mechanisms. Endocrinology (2016) 157(10):4041-54. doi: 10.1210/en.20161259

42. Chu A, Thamotharan S, Ganguly A, Wadehra M, Pellegrini M, Devaskar SU. Gestational Food Restriction Decreases Placental Interleukin-10 Expression and Markers of Autophagy and Endoplasmic Reticulum Stress in Murine Intrauterine Growth Restriction. Nutr Res (2016) 36(10):1055-67. doi: 10.1016/j.nutres.2016.08.001

43. Butler B, De Dios R, Nguyen L, McKenna S, Ghosh S, Wright CJ. Developmentally Regulated Innate Immune NFkappaB Signaling Mediates IL-1alpha Expression in the Perinatal Murine Lung. Front Immunol (2019) 10:1555. doi: 10.3389/fimmu.2019.01555

44. Nguyen L, Sandoval J, De Dios R, Yihdego E, Zarate M, Castro O, et al. The Hepatic Innate Immune Response Is Lobe-Specific in a Murine Model Endotoxemia. Innate Immun (2019) 25(2):144-54. doi: 10.1177/ 1753425918823900

45. Akira S, Uematsu S, Takeuchi O. Pathogen Recognition and Innate Immunity. Cell (2006) 124(4):783-801. doi: 10.1016/j.cell.2006.02.015

46. Karin M, Ben-Neriah Y. Phosphorylation Meets Ubiquitination: The Control of NF-[Kappa]B Activity. Annu Rev Immunol (2000) 18:621-63. doi: 10.1146/ annurev.immunol.18.1.621

47. Lu YC, Yeh WC, Ohashi PS. LPS/TLR4 Signal Transduction Pathway. Cytokine (2008) 42(2):145-51. doi: 10.1016/j.cyto.2008.01.006

48. Kawagoe T, Sato S, Matsushita K, Kato H, Matsui K, Kumagai Y, et al. Sequential Control of Toll-Like Receptor-Dependent Responses by IRAK1 and IRAK2. Nat Immunol (2008) 9(6):684-91. doi: 10.1038/ni.1606

49. Akira S, Takeda K. Toll-Like Receptor Signalling. Nat Rev Immunol (2004) 4 (7):499-511. doi: 10.1038/nri1391

50. Christian F, Smith EL, Carmody RJ. The Regulation of NF-kappaB Subunits by Phosphorylation. Cells (2016) 5(1):12. doi: 10.3390/cells5010012

51. Papa S, Bubici C, Zazzeroni F, Franzoso G. Mechanisms of Liver Disease: Cross-Talk Between the NF-kappaB and JNK Pathways. Biol Chem (2009) 390 (10):965-76. doi: 10.1515/BC.2009.111 
52. Ghosh S, May MJ, Kopp EB. NF-Kappa B and Rel Proteins: Evolutionarily Conserved Mediators of Immune Responses. Annu Rev Immunol (1998) 16:225-60. doi: 10.1146/annurev.immunol.16.1.225

53. Amu S, Hahn-Zoric M, Malik A, Ashraf R, Zaman S, Kjellmer I, et al. Cytokines in the Placenta of Pakistani Newborns With and Without Intrauterine Growth Retardation. Pediatr Res (2006) 59(2):254-8. doi: 10.1203/01.pdr.0000196332.37565.7d

54. Chatrath R, Saili A, Jain M, Dutta AK. Immune Status of Full-Term Small-forGestational Age Neonates in India. J Trop Pediatr (1997) 43(6):345-8. doi: 10.1093/tropej/43.6.345

55. Contreras YM, Yu X, Hale MA, Callaway CW, Bareyan D, McKnight RA, et al. Intrauterine Growth Restriction Alters T-Lymphocyte Cell Number and Dual Specificity Phosphatase 1 Levels in the Thymus of Newborn and Juvenile Rats. Pediatr Res (2011) 70(2):123-9. doi: 10.1203/PDR.0b013e31821f6e75

56. Baek O, Sangild PT, Thymann T, Nguyen DN. Growth Restriction and Systemic Immune Development in Preterm Piglets. Front Immunol (2019) 10:2402. doi: 10.3389/fimmu.2019.02402

57. Oeckinghaus A, Ghosh S. The NF-kappaB Family of Transcription Factors and Its Regulation. Cold Spring Harb Perspect Biol (2009) 1(4):a000034. doi: 10.1101/cshperspect.a000034

58. Klement JF, Rice NR, Car BD, Abbondanzo SJ, Powers GD, Bhatt PH, et al. IkappaBalpha Deficiency Results in a Sustained NF-kappaB Response and Severe Widespread Dermatitis in Mice. Mol Cell Biol (1996) 16(5):2341-9. doi: $10.1128 / \mathrm{mcb} \cdot 16.5 .2341$

59. Rupec RA, Jundt F, Rebholz B, Eckelt B, Weindl G, Herzinger T, et al. StromaMediated Dysregulation of Myelopoiesis in Mice Lacking I Kappa B Alpha. Immunity (2005) 22(4):479-91. doi: 10.1016/j.immuni.2005.02.009

60. Rao P, Hayden MS, Long M, Scott ML, West AP, Zhang D, et al. IkappaBbeta Acts to Inhibit and Activate Gene Expression During the Inflammatory Response. Nature (2010) 466(7310):1115-9. doi: 10.1038/nature09283

61. Auphan N, DiDonato JA, Rosette C, Helmberg A, Karin M. Immunosuppression by Glucocorticoids: Inhibition of NF-Kappa B Activity Through Induction of I Kappa B Synthesis. Science (1995) 270 (5234):286-90. doi: 10.1126/science.270.5234.286

62. Peng HB, Libby P, Liao JK. Induction and Stabilization of I Kappa B Alpha by Nitric Oxide Mediates Inhibition of NF-Kappa B. J Biol Chem (1995) 270 (23):14214-9. doi: 10.1074/jbc.270.23.14214

63. Trescher K, Bernecker O, Fellner B, Gyongyosi M, Schafer R, Aharinejad S, et al. Inflammation and Postinfarct Remodeling: Overexpression of IkappaB Prevents Ventricular Dilation via Increasing TIMP Levels. Cardiovasc Res (2006) 69(3):746-54. doi: 10.1016/j.cardiores.2005.11.027

64. Suetsugu H, Iimuro Y, Uehara T, Nishio T, Harada N, Yoshida M, et al. Nuclear Factor \{Kappa\}B Inactivation in the Rat Liver Ameliorates Short Term Total Warm Ischaemia/Reperfusion Injury. Gut (2005) 54(6):835-42. doi: 10.1136/gut.2004.043034

65. Zhao X, Ross EJ, Wang Y, Horwitz BH. Nfkb1 Inhibits LPS-Induced IFN-Beta and IL-12 P40 Production in Macrophages by Distinct Mechanisms. PLoS One (2012) 7(3):e32811. doi: 10.1371/journal.pone.0032811

66. Porta C, Rimoldi M, Raes G, Brys L, Ghezzi P, Di Liberto D, et al. Tolerance and M2 (Alternative) Macrophage Polarization Are Related Processes Orchestrated by P50 Nuclear Factor kappaB. Proc Natl Acad Sci USA (2009) 106(35):14978-83. doi: 10.1073/pnas.0809784106

67. Bonizzi G, Karin M. The Two NF-kappaB Activation Pathways and Their Role in Innate and Adaptive Immunity. Trends Immunol (2004) 25(6):280-8. doi: 10.1016/j.it.2004.03.008

68. Li Q, Verma IM. NF-kappaB Regulation in the Immune System. Nat Rev Immunol (2002) 2(10):725-34. doi: 10.1038/nri910

69. Kanaan Z, Gardner S, Carruba C, Mattingly J, Druen D, Cheadle WG. Macrophage Genetic Reprogramming During Chronic Peritonitis Is Augmented by LPS Pretreatment. J Surg Res (2012) 175(2):289-97. doi: 10.1016/j.jss.2011.04.051

70. Dai JN, Zong Y, Zhong LM, Li YM, Zhang W, Bian LG, et al. Gastrodin Inhibits Expression of Inducible NO Synthase, Cyclooxygenase-2 and Proinflammatory Cytokines in Cultured LPS-Stimulated Microglia via MAPK Pathways. PLoS One (2011) 6(7):e21891. doi: 10.1371/journal.pone.0021891

71. Goldenberg RL, Andrews WW, Faye-Petersen OM, Goepfert AR, Cliver SP, Hauth JC. The Alabama Preterm Birth Study: Intrauterine Infection and Placental Histologic Findings in Preterm Births of Males and Females Less
Than 32 Weeks. Am J Obstet Gynecol (2006) 195(6):1533-7. doi: 10.1016/ j.ajog.2006.05.023

72. Zazara DE, Arck PC. Developmental Origin and Sex-Specific Risk for Infections and Immune Diseases Later in Life. Semin Immunopathol (2019) 41(2):137-51. doi: 10.1007/s00281-018-0713-x

73. Bouman A, Heineman MJ, Faas MM. Sex Hormones and the Immune Response in Humans. Hum Reprod Update (2005) 11(4):411-23. doi: $10.1093 /$ humupd/dmi008

74. Fish EN. The X-Files in Immunity: Sex-Based Differences Predispose Immune Responses. Nat Rev Immunol (2008) 8(9):737-44. doi: 10.1038/nri2394

75. Zanno AE, Romer MA, Fox L, Golden T, Jaeckle-Santos L, Simmons RA, et al. Reducing Th2 Inflammation Through Neutralizing IL-4 Antibody Rescues Myelination in IUGR Rat Brain. J Neurodev Disord (2019) 11(1):34. doi: 10.1186/s11689-019-9297-6

76. Wixey JA, Lee KM, Miller SM, Goasdoue K, Colditz PB, Tracey Bjorkman S, et al. Neuropathology in Intrauterine Growth Restricted Newborn Piglets Is Associated With Glial Activation and Proinflammatory Status in the Brain. J Neuroinflamm (2019) 16(1):5. doi: 10.1186/s12974-018-1392-1

77. Guo R, Hou W, Dong Y, Yu Z, Stites J, Weiner CP. Brain Injury Caused by Chronic Fetal Hypoxemia Is Mediated by Inflammatory Cascade Activation. Reprod Sci (2010) 17(6):540-8. doi: 10.1177/1933719110364061

78. Campbell LR, Pang Y, Ojeda NB, Zheng B, Rhodes PG, Alexander BT. Intracerebral Lipopolysaccharide Induces Neuroinflammatory Change and Augmented Brain Injury in Growth-Restricted Neonatal Rats. Pediatr Res (2012) 71(6):645-52. doi: 10.1038/pr.2012.26

79. Lindner U, Tutdibi E, Binot S, Monz D, Hilgendorff A, Gortner L. Levels of Cytokines in Umbilical Cord Blood in Small for Gestational Age Preterm Infants. Klin Padiatr (2013) 225(2):70-4. doi: 10.1055/s-0033-1334879

80. Neta GI, von Ehrenstein OS, Goldman LR, Lum K, Sundaram R, Andrews W, et al. Umbilical Cord Serum Cytokine Levels and Risks of Small-forGestational-Age and Preterm Birth. Am J Epidemiol (2010) 171(8):859-67. doi: 10.1093/aje/kwq028

81. Troger B, Muller T, Faust K, Bendiks M, Bohlmann MK, Thonnissen S, et al. Intrauterine Growth Restriction and the Innate Immune System in Preterm Infants of $</=32$ Weeks Gestation. Neonatology (2013) 103(3):199-204. doi: $10.1159 / 000343260$

82. Lausten-Thomsen U, Olsen M, Greisen G, Schmiegelow K. Inflammatory Markers in Umbilical Cord Blood From Small-for-Gestational-Age Newborns. Fetal Pediatr Pathol (2014) 33(2):114-8. doi: 10.3109/ 15513815.2013.879239

83. Rocha G, Proenca E, Guedes A, Carvalho C, Areias A, Ramos JP, et al. Cord Blood Levels of IL-6, IL-8 and IL-10 May Be Early Predictors of Bronchopulmonary Dysplasia in Preterm Newborns Small for Gestational Age. Dis Markers (2012) 33(1):51-60. doi: 10.3233/DMA-2012-0903

84. Zhong X, Li W, Huang X, Zhang L, Yimamu M, Raiput N, et al. Impairment of Cellular Immunity Is Associated With Overexpression of Heat Shock Protein 70 in Neonatal Pigs With Intrauterine Growth Retardation. Cell Stress Chaperones (2012) 17(4):495-505. doi: 10.1007/s12192-012-0326-6

85. Polanyi L, Niessen CM, Vohlen C, Stinn J, Kretschmer T, Jentgen V, et al. Intrauterine Growth Restriction Induces Skin Inflammation, Increases TSLP and Impairs Epidermal Barrier Function. J Mol Med (Berl) (2020) 98(2):27989. doi: 10.1007/s00109-019-01867-w

86. Roman A, Desai N, Rochelson B, Gupta M, Solanki M, Xue X, et al. Maternal Magnesium Supplementation Reduces Intrauterine Growth Restriction and Suppresses Inflammation in a Rat Model. Am J Obstet Gynecol (2013) 208 (5):383.e1-7. doi: 10.1016/j.ajog.2013.03.001

87. Suhag A, Berghella V. Intrauterine Growth Restriction (IUGR): Etiology and Diagnosis. Curr Obstet Gynecol Rep (2013) 2(2):102-11.

88. Zhou Y, Huang X, Zhao T, Qiao M, Zhao X, Zhao M, et al. Hypoxia Augments LPS-Induced Inflammation and Triggers High Altitude Cerebral Edema in Mice. Brain Behav Immun (2017) 64:266-75. doi: 10.1016/j.bbi.2017.04.013

89. Fang H, Liu A, Chen X, Cheng W, Dirsch O, Dahmen U. The Severity of LPS Induced Inflammatory Injury Is Negatively Associated With the Functional Liver Mass After LPS Injection in Rat Model. J Inflamm (Lond) (2018) 15:21. doi: 10.1186/s12950-018-0197-4

90. Robinson MK, Rustum RR, Chambers EA, Rounds JD, Wilmore DW, Jacobs DO. Starvation Enhances Hepatic Free Radical Release Following Endotoxemia. J Surg Res (1997) 69(2):325-30. doi: 10.1006/jsre.1997.5062 
91. Bonvini A, Rogero MM, Coqueiro AY, Raizel R, Bella LM, Fock RA, et al. Effects of Different Branched-Chain Amino Acids Supplementation Protocols on the Inflammatory Response of LPS-Stimulated RAW 264.7 Macrophages. Amino Acids (2021) 53(4):597-607. doi: 10.1007/s00726-02102940-W

92. Klein K, Fuchs GJ, Kulapongs P, Mertz G, Suskind RM, Olson RE. Endotoxemia in Protein-Energy Malnutrition. J Pediatr Gastroenterol Nutr (1988) 7(2):225-8. doi: 10.1097/00005176-198803000-00012

93. Sakaguchi S, Furusawa S. Oxidative Stress and Septic Shock: Metabolic Aspects of Oxygen-Derived Free Radicals Generated in the Liver During Endotoxemia. FEMS Immunol Med Microbiol (2006) 47(2):167-77. doi: 10.1111/j.1574-695X.2006.00072.X

94. Amdi C, Krogh U, Flummer C, Oksbjerg N, Hansen CF, Theil PK. Intrauterine Growth Restricted Piglets Defined by Their Head Shape Ingest Insufficient Amounts of Colostrum. J Anim Sci (2013) 91(12):5605-13. doi: 10.2527 /jas.2013-6824

95. Attig L, Brisard D, Larcher T, Mickiewicz M, Guilloteau P, Boukthir S, et al. Postnatal Leptin Promotes Organ Maturation and Development in IUGR Piglets. PLoS One (2013) 8(5):e64616. doi: 10.1371/journal. pone.0064616
Conflict of Interest: The authors declare that the research was conducted in the absence of any commercial or financial relationships that could be construed as a potential conflict of interest.

The reviewer SM has declared a past collaboration with some of the authors $\mathrm{RD}$, LS, PR, and CW to the handling editor at the time of review.

Publisher's Note: All claims expressed in this article are solely those of the authors and do not necessarily represent those of their affiliated organizations, or those of the publisher, the editors and the reviewers. Any product that may be evaluated in this article, or claim that may be made by its manufacturer, is not guaranteed or endorsed by the publisher.

Copyright (c) 2021 Zarate, De Dios, Balasubramaniyan, Zheng, Sherlock, Rozance and Wright. This is an open-access article distributed under the terms of the Creative Commons Attribution License (CC BY). The use, distribution or reproduction in other forums is permitted, provided the original author(s) and the copyright owner(s) are credited and that the original publication in this journal is cited, in accordance with accepted academic practice. No use, distribution or reproduction is permitted which does not comply with these terms. 